\title{
Microwave-assisted brazing of alumina ceramics for electron tube applications
}

\author{
MAYUR SHUKLA ${ }^{1,2}$, SUMANA GHOSH ${ }^{2, *}$, NANDADULAL DANDAPAT ${ }^{2}$, ASHIS K MANDAL ${ }^{2}$ \\ and VAMSI K BALLA ${ }^{2}$ \\ ${ }^{1}$ Academy of Scientific and Innovative Research (AcSIR), CSIR-Central Glass and Ceramic Research Institute, \\ Kolkata 700 032, India \\ ${ }^{2}$ CSIR-Central Glass and Ceramic Research Institute (CSIR-CGCRI), Kolkata 700 032, India
}

MS received 12 August 2015; accepted 6 November 2015

\begin{abstract}
Alumina was joined with alumina using microwave-assisted and conventional brazing methods at $960^{\circ} \mathrm{C}$ for $15 \mathrm{~min}$ using TiCuSil $(68.8 \mathrm{Ag}-26.7 \mathrm{Cu}-4.5 \mathrm{Ti}$ in wt.\%) as the brazing alloy. The brazed joints were characterized by X-ray diffraction, scanning electron microscopy, energy dispersive X-ray analysis, Vickers microhardness evaluation, brazing strength measurement and helium leak test. X-ray diffraction analysis confirmed the formation of Ti-based compounds at the substrate-filler alloy interfaces of the microwave and conventionally brazed joints. The elemental compositions at the joint cross-section were determined by energy dispersive X-ray analysis. Vickers microhardness measurement indicated reliable joint performance for the microwave-assisted brazed joints during actual application in an electron tube. Brazing strength measurement and helium leak test provided the evidence for good alumina-alumina joint formation.
\end{abstract}

Keywords. Joining; ceramics; interfaces; microhardness; brazing strength; Helium leak test.

\section{Introduction}

Alumina ceramics are used in wide range of applications due to their high-temperature strength, exceptional resistance to wear and corrosion, low thermal conductivity and low coefficients of thermal expansion. Large and complex ceramic components are difficult to fabricate and therefore joining is the preferred method. Among several ceramic joining processes, active metal brazing is one of the most extensively used joining techniques for ceramic-ceramic joining [1]. Since the wettability of ceramic materials is very low, bonding is promoted with the use of an active filler alloy in active metal brazing method. The active filler alloy contains small amount of an active element that can improve the wettability of the ceramics. Active metal brazing with Ti as the active element is the most popular method [2].

Microwave heating [3,4] is a novel technique for processing of materials and it is fundamentally different from conventional heating, where thermal energy is delivered to the surface of the material by radiation and/or convection that reaches the bulk of the material via conduction. On contrary, in microwave processing the heat is generated within the material through molecular interaction with the electromagnetic field. Microwaves can penetrate the material and supply energy generating heat throughout the volume of the material resulting in volumetric heating [5]. The microwave processing of materials offers several advantages over conventional

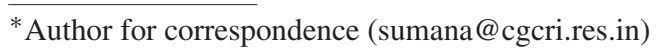

heating methods, such as unique microstructure and properties, improved product performance, reduced processing time and temperature, time and energy savings, manufacturing cost reduction and new material synthesis [5]. Additionally, microwaves can couple with the higher loss tangent material selectively when it is in contact with materials of different dielectric properties due to energy transfer at a molecular level. Hence, microwaves can be used for selective heating of the materials [6]. Selective heating phenomenon can be used for various applications. During conventional joining of ceramics considerable time and energy is wasted to heat up the interface by conduction through the substrates, whereas the joint interface can be heated in situ by incorporating a higher loss material at the interface during microwave joining [5-7].

Several excellent reviews [8-12] have summarized the status of microwave processing research. The microwave technology has been successfully employed for a number of industrial applications [7]. Oxide materials such as $\mathrm{Al}_{2} \mathrm{O}_{3}$ and $\mathrm{SiO}_{2}$ are transparent to microwaves at room temperature. These transparent materials can absorb microwaves by adding conductive phases or by using hybrid heating. The technique of using the heat radiated by the absorbers to raise the temperature of transparent materials has been termed microwave hybrid heating (MHH) [7]. Meek and Blake [13] first reported the joining of two alumina plates with a glassy interlayer in a microwave oven. Fukushima et al [14] utilized microwave heating for ceramic joining. They developed a new butt joining method for ceramics using microwave heating. Ceramic matrix composites have increasing demand 
for various applications due to their enhanced toughness and wear resistance. Aravindan and Krishnamurthy [15] joined sintered alumina-30\% zirconia ceramic composites by $\mathrm{MHH}$ with sodium silicate glass powder as an interlayer. Ahmed and Siores [16] joined 48\% alumina-32\% zirconia-20\% silica ceramics by microwave heating.

Few researchers have performed ceramic to ceramic joining by microwave heating technique. There is a lack of information regarding the microwave brazing of ceramics and the present work is an attempt to fill this gap. Further, the alumina-alumina brazed joint should cope with the thermal shock in an electron tube application. Therefore, investigation on interfacial stiffness of the alumina-alumina brazed joint is crucial. We have already studied alumina-alumina, alumina-graphite and alumina-monel superalloy conventionally brazed joints for electron tube applications $[17,18]$. Especially, the fabrication of traveling wave tube (TWT) needs the alumina-alumina joining [19]. In the present study, the interfacial stiffness of the alumina-alumina microwave brazed joint was evaluated to find its suitability during actual service application in an electron tube.

\section{Materials and methods}

Pure alumina powder (Alcoa, USA; $99.99 \%$ purity) was cold isostatically pressed (EPSI NV, SO 10036, Belgium) to cylindrical shapes at $150 \mathrm{MPa}$ pressure. The green powder compacts were dried and calcined in an electrical furnace at $800^{\circ} \mathrm{C}$ for $1 \mathrm{~h}$ (ELECTROHEAT, Model No. EN170QT, Naskar \& Co., Howrah, India), then cut and finally sintered at $1600^{\circ} \mathrm{C}$ for $2 \mathrm{~h}$. The sintered alumina specimens had a dimension of $12 \mathrm{~mm}$ diameter and $3 \mathrm{~mm}$ thickness. The surfaces of sintered alumina specimens were ground using a grinding machine (BAINLINE Belt Linishing machine, Chennai Metco. Limited, Chennai, India) and polished using a polishing machine (Leco Corporation, USA) with 6, 3 and $0.25 \mu \mathrm{m}$ diamond pastes (Buehler USA). Samples were ultrasonically cleaned with acetone before the microwave joining. TiCuSil paste $(68.8 \mathrm{Ag}-26.7 \mathrm{Cu}-4.5 \mathrm{Ti}$ in wt.\%, WESGO Inc., Hayward, CA 94544, USA) was used as filler metal (thickness $\sim 100 \mu \mathrm{m}$ ).

A multimode microwave furnace with a magnetron having frequency of $2.45 \mathrm{GHz}$ and maximum output power of 3 kW (Enerzi Microwave Systems Pvt. Limited, Bangalore, India) was used for joining. The samples were placed in an alumina disc insulated by microwave transparent casket insulating box. The top cover of the insulating box was facilitated with a hole of $20 \mathrm{~mm}$ diameter to monitor temperature through a non-contact IR pyrometer $\left(260-1800^{\circ} \mathrm{C}\right)$. Accuracy of temperature measurement was $\pm 0.3 \%$ of the measured value $+1{ }^{\circ} \mathrm{C}$ with adjustable emissivity $(\varepsilon: 0.1-1.0)$. The specimens were brazed by microwave heating at $960^{\circ} \mathrm{C}$ for 15 min using TiCuSil metallic paste with a heating and cooling rate of $25^{\circ} \mathrm{C} \mathrm{min}-1$ in an argon atmosphere. Total processing time was $\sim 2 \mathrm{~h}$ for microwave brazing of alumina ceramics. Microwave output power (MW power) and temperature were recorded by DAQSOFT software in a separate computer. A separate $\mathrm{kWh}$ meter was also connected to the furnace to monitor mainly the consumption of instant electrical power and total power consumption for overall heating operation including utilities. The metallic materials in powder form absorb the microwaves. Fine metal powder can absorb the microwave radiation very rapidly. In this case, microwaves heated the fine powdered metallic alloy braze material in paste form selectively at room temperature resulting in microwave brazing of alumina ceramics $[20,21]$. SiC powder was used as a susceptor to initiate coupling of microwave with the alumina substrate. Therefore, fine powdered metallic paste was heated by the microwaves as well as by the conduction method through the alumina substrate leading to hybrid heating. Second set of samples were brazed inside a high vacuum furnace (Hindhivac Private Limited, Bangalore, India) with a vacuum of $5 \times 10^{-6}$ mbar under identical brazing temperature and time. Heating and cooling rate was maintained similar to that followed in our earlier paper [18]. Conventional brazing operation took total processing time of $\sim 9 \mathrm{~h}$. Phase identification of the interfacial reaction products was carried out by X-ray diffraction (XRD; PW 1710, Philips Research Laboratory, Eindhoven, The Netherlands) using $\mathrm{CuK} \alpha$ radiation (45 kV, $35 \mathrm{~mA}$ ). Microstructural observations were performed by scanning electron microscopy (SEM; Phenom Pro-X, The Netherlands) and elemental composition was determined by energy dispersive X-ray (EDX) analysis (Phenom Pro-X). Microhardness was evaluated across the joint cross-section by a Vickers hardness tester (ESEWAY, 410 series, Bowers Group, UK) at a load of $100 \mathrm{~g}$ with $30 \mathrm{~s}$ loading/unloading time. For a particular type of specimen, five specimens were examined. In the case of each specimen 25 numbers of individual data were taken. Large numbers of data were taken to avoid the deviations at the scale of local microstructure of the specimen and large scatter in the data. The brazing strength measurement was conducted by using a universal tester (Romulus, QUAD Group Inc., USA). Helium leak test was performed by using a helium leak detector (Adixen, ASM 142, France).

\section{Results and discussion}

Temperature-MW power and time (T-P-t) profile for microwave brazing was recorded as presented in figure 1. The maximum MW power needed to heat up aluminametal paste-alumina assembly was around $2 \mathrm{~kW}$ until $800^{\circ} \mathrm{C}$ and further heating could be made with less MW power indicating good microwave absorption above this temperature. Further, the requirement of MW power was reduced to $0.5 \mathrm{~kW}$ at $960^{\circ} \mathrm{C}$. Total power during the microwave brazing operation was recorded as $4.8 \mathrm{kWh}$ including chiller power load. The electrical power could be further reduced by using air-cooled magnetron. The power requirement during conventional brazing cycle was significantly higher (110 $\mathrm{kWh})$ than that noted during microwave brazing. In 


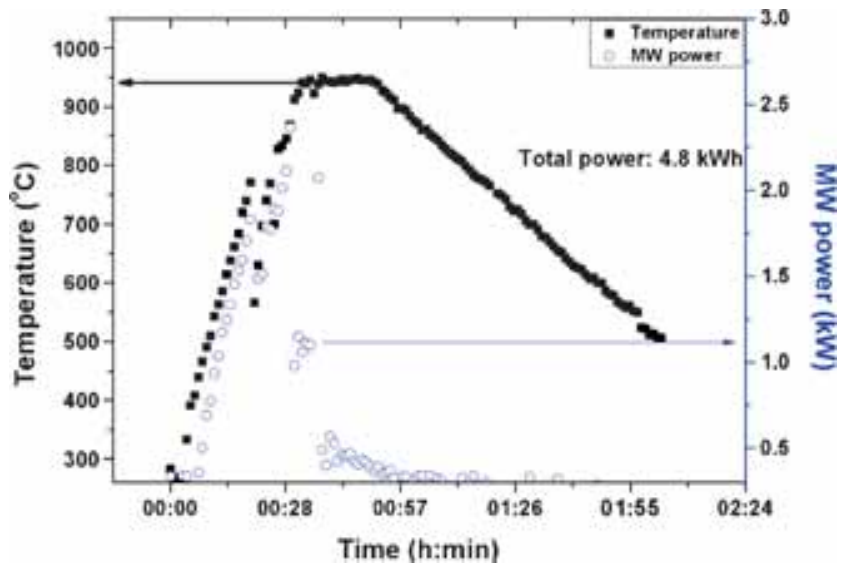

Figure 1. Temperature-microwave power and time (T-P-t) profile during microwave brazing operation.

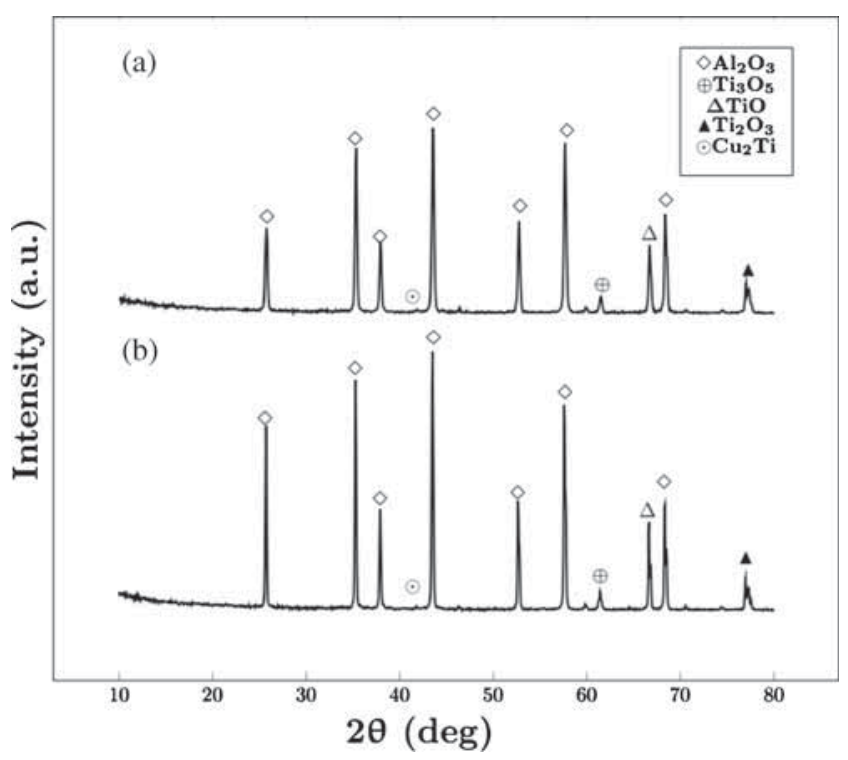

Figure 2. XRD analysis of brazed joints: (a) conventional and (b) microwave.

addition, alumina-alumina brazing by microwave heating could be performed within $\sim 2 \mathrm{~h}$ whereas it was achieved within $\sim 9 \mathrm{~h}$ by conventional heating method. Thus, shorter processing time along with less energy consumption enabled microwave processing as a potential economical material processing method in view of alumina-alumina brazing over conventional heating method.

$\mathrm{Ag}-\mathrm{Cu}-\mathrm{Ti}$ system wets almost all the ceramics, as $\mathrm{Ti}$ increases the melting point and fluidity of the braze alloy [22]. Moreover, brittle reaction products are found at the interface since the active element induces excessive interfacial reaction [2]. In our samples also Ti was found to react with alumina and formed several reaction products at the interfaces. XRD identified Ti-based compounds such as TiO, $\mathrm{Ti}_{2} \mathrm{O}_{3}$ and $\mathrm{Ti}_{3} \mathrm{O}_{5}$ as reaction products at all the interfaces of the conventionally brazed joint as well as the microwave brazed joint (figure 2).
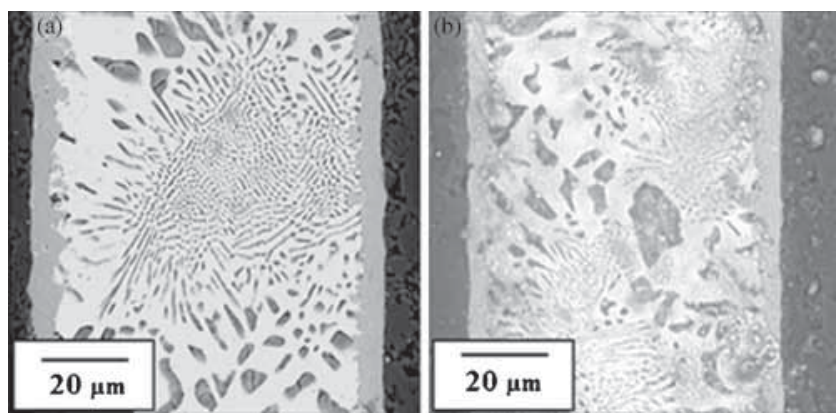

Figure 3. SEM micrographs of (a) conventional and (b) microwave brazed joints.

SEM images of microwave and conventionally brazed joints (figure 3) showed that the interfacial regions were devoid of any crack or defect. The reaction layer thickness of conventionally brazed joint was $\sim 6 \mu \mathrm{m}$, while it was $\sim 5 \mu \mathrm{m}$ in case of the microwave brazed joint under similar processing conditions $\left(960^{\circ} \mathrm{C}, 15 \mathrm{~min}\right)$. The reaction layer thickness of conventionally brazed joint was increased due to enhanced diffusion of $\mathrm{Ti}, \mathrm{O}$ and $\mathrm{Cu}$ elements towards the interfacial regions of braze and substrate on account of prolonged duration of total brazing cycle.

EDX analysis identified the presence of $\mathrm{Ag}, \mathrm{Cu}, \mathrm{Ti}, \mathrm{Al}$ and $\mathrm{O}$ elements at the interfacial regions (figure 4). The EDX analysis determined the elemental compositions at the selective points of the joint cross-section. EDX data supported the $\mathrm{X}$-ray diffraction results. It was observed that braze region had two types of distinct zones, i.e., grey and white zones. In the case of conventionally brazed joint the grey zone of the braze consisted of mainly $\mathrm{Ag}$ element, whereas $\mathrm{Cu}$ was detected as a major element in the white zone. On the contrary, Ag was major element in both the grey and white zones in the microwave brazed joint. Presence of aluminium and oxygen elements in the braze region can be ascribed to the diffusion of these elements towards the joint area.

Vickers microhardness measurement (figure 5) showed excellent transition between the substrate materials of the microwave and conventionally brazed joints, indicating reliable joint performance during service. In both the cases, the microhardness of the braze region was quite lower than that of alumina substrate, leading to stress relaxation of the joints through plastic deformation of the soft braze region $[23,24]$. It was assumed that the formation of Ti-based compounds caused intermediate microhardness values of the aluminabraze interfacial regions relating to those values of alumina and braze regions. However, the lower interfacial hardness was observed in the case of alumina-alumina joint brazed using microwave heating. The interfacial Vickers microhardness values were $612 \pm 65$ and $984 \pm 85 \mathrm{HV}$ for microwave and conventionally brazed joints, respectively. This can be ascribed to the formation of thinner reaction layer containing relatively less amount of brittle reaction products during microwave brazing compared to that obtained by conventional brazing method. Vickers microhardness values of the braze region were $147 \pm 15$ and $166 \pm 18 \mathrm{HV}$ for the 


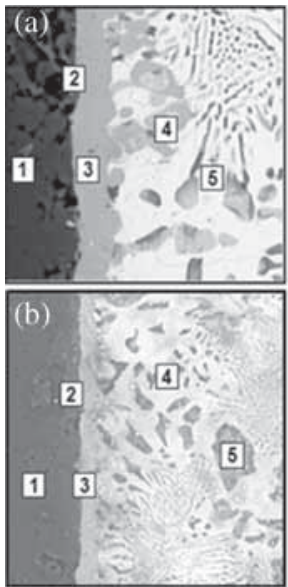

\begin{tabular}{cccccc}
\hline $\begin{array}{c}\text { Elements } \\
\text { (wt.\%) }\end{array}$ & $\begin{array}{c}\text { Alumina } \\
\text { region } \\
(1)\end{array}$ & $\begin{array}{c}\text { Interfacial } \\
\text { region } \\
(2)\end{array}$ & $\begin{array}{c}\text { Reaction } \\
\text { region } \\
(3)\end{array}$ & $\begin{array}{c}\text { Grey } \\
\text { region } \\
(4)\end{array}$ & $\begin{array}{c}\text { White } \\
\text { region } \\
(5)\end{array}$ \\
\hline $\mathrm{Ag}$ & 2.5 & 4.4 & 4.8 & 34.2 & 18.1 \\
$\mathrm{Cu}$ & 0 & 18.9 & 19.4 & 11.5 & 36.4 \\
$\mathrm{Ti}$ & 0.3 & 21.1 & 21.3 & 8.6 & 1.1 \\
$\mathrm{Al}$ & 43.9 & 24.0 & 23.1 & 18.3 & 22.3 \\
$\mathrm{O}$ & 53.3 & 31.6 & 31.4 & 27.4 & 22.1 \\
\hline \multicolumn{7}{c}{} & \multicolumn{1}{c}{${ }^{2}$} & & & \\
\hline Elements & Alumina & Interfacial & Reaction & Grey & White \\
(wt.\%) & region & region & region & region & region \\
& $(1)$ & $(2)$ & $(3)$ & $(4)$ & $(5)$ \\
\hline $\mathrm{Ag}$ & 3.1 & 9.0 & 6.3 & 57.7 & 43.9 \\
$\mathrm{Cu}$ & 0.6 & 4.6 & 1.8 & 2.8 & 11.2 \\
$\mathrm{Ti}$ & 0.5 & 2.3 & 26.2 & 0.6 & 0 \\
$\mathrm{Al}$ & 44.5 & 29.1 & 14.7 & 13.1 & 14.1 \\
$\mathrm{Si}$ & 0 & 0 & 0.5 & 0 & 0 \\
$\mathrm{O}$ & 51.3 & 55.0 & 50.5 & 25.8 & 30.8 \\
\hline
\end{tabular}

Figure 4. SEM images showing magnified interfacial regions of (a) conventional and (b) microwave brazed joints and their corresponding point-EDX analysis at five different points.

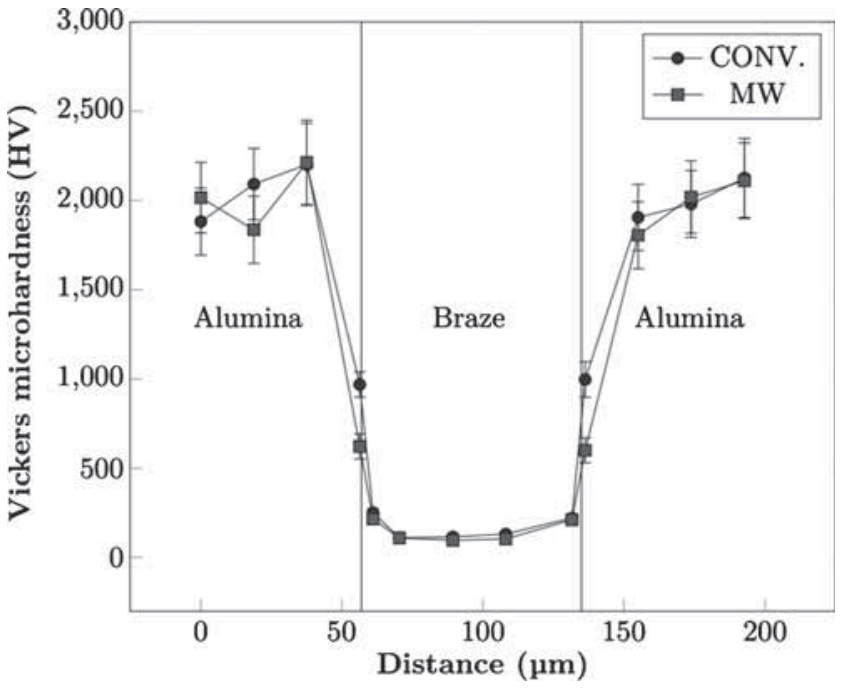

Figure 5. Vickers microhardness measurements across the crosssections of the microwave and conventionally brazed joints.

microwave and conventionally brazed joints, respectively. Thus, it is obvious that the stiffness of the microwave brazed joint was lower indicating less possibility for brittle failure of the joint.

Figure 6 shows applied force and brazing strength values for the conventional and microwave brazed joints. The brazing strength was measured using the following equation [25].

$$
Q=4 F / \pi d^{2},
$$

where $F$ is the breaking force and $d$ is the diameter of the loading fixture. The brazing strength was measured to be 33 and $34 \mathrm{MPa}$ for conventional and microwave brazed joints, respectively. During brazing strength measurement, the specimen did not rupture at the interfacial regions between braze and substrate. However, failure occurred at the gripping portion of the alumina substrate. Therefore, it can be said that the brazing strength of both the microwave and conventionally
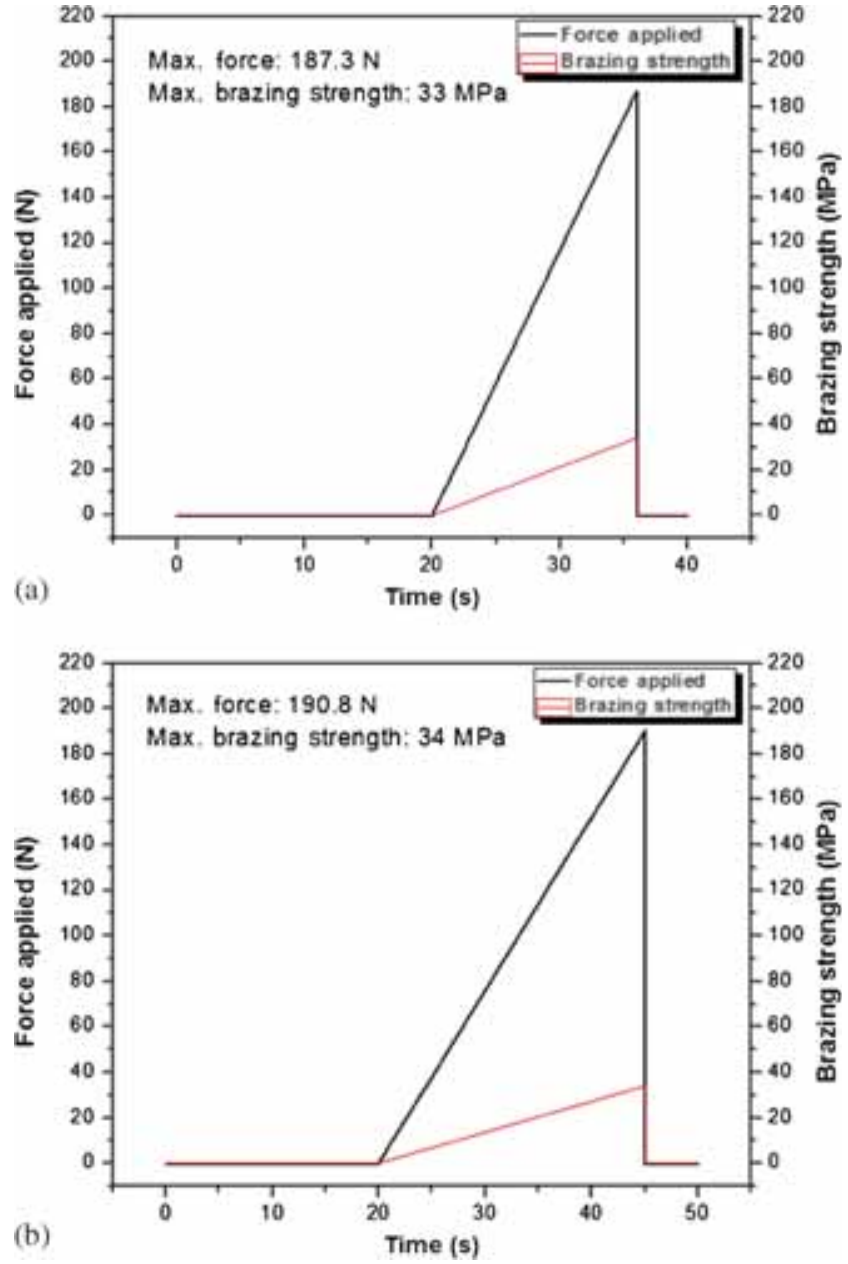

Figure 6. Maximum applied force and brazing strength for (a) conventional and (b) microwave brazed joints.

brazed joints was quite good. Substantial difference in the brazing strength values of microwave and conventionally brazed joints was not observed in the present case, as failure 
of the alumina substrate took place before separation of the braze and substrate. The helium leak test showed that the microwave and conventionally brazed joints can withstand up to $1 \times 10^{-9}$ Torr pressure without any leakage and thereby, indicating hermetic characteristic of both the microwave and conventionally processed alumina-alumina joints.

\section{Conclusion}

In the present study, alumina discs were successfully joined by microwave-assisted brazing method and conventional brazing method under identical processing conditions. However, microwave-assisted brazing decreased total processing time leading to energy saving and reduction of manufacturing cost. Intensive chemical reactions had taken place at the interfaces of both the microwave and conventionally brazed joints. The reaction layer was found to be slightly thinner in the case of microwave brazed joint than that of the conventionally brazed joint. The interfacial Vickers hardness was observed to be lower for the microwave brazed joint and thereby, indicating lower stiffness of the microwave brazed joint. The brazing strength was also comparable for microwave and conventionally brazed joints. Helium leak test indicated good hermicity for the microwave and conventionally brazed joints. The experimental results demonstrated that microwave heating is a promising cost-effective technique for joining alumina ceramics to fabricate very high power electron tube components.

\section{Acknowledgement}

This work was financially supported by CSIR, India, under 12FYP network project titled 'Very High Power Microwave Tubes: Design and Development Capabilities (MTDDC)', Grant no. PSC0101.

\section{References}

[1] Fernie J A, Drew R A L and Knowles K M 2009 J. Int. Mater. Rev. 54283
[2] Nicholas M G, Valentine T M and Waite M J 1980 J. Mater. Sci. 152197

[3] Sheppard L M 1988 Ceram. Bull. 671556

[4] Katz J D 1992 Annu. Rev. Mater. Sci. 22153

[5] Sutton W H 1989 Am. Ceram. Soc. Bull. 68376

[6] Thostenson E T and Chou T W 1999 Composites part A 30 1055

[7] Das S, Mukhopadhyay A K, Datta S and Basu D 2008 Bull. Mater. Sci. 31943

[8] Clark D and Sutton W H 1996 Annu. Rev. Mater. Sci. 26299

[9] Schiffman R F 1995 Ceram. Trans. 597

[10] Sutton W H 1992 Mat. Res. Soc. Symp. Proc. 2693

[11] Palaith D and Silberglitt R 1989 Ceram. Bull. 681601

[12] Yin T Y, Varadan V V, Varadan V K and Conway J C 1991 Ceram. Trans. 21507

[13] Meek T T and Blake R D 1986 J. Mater. Sci. Lett. 5270

[14] Fukushima H T, Yamanaka T and Matsui T M 1990 J. Mater. Res. 5397

[15] Aravindan S and Krishnamurthy R 1999 Mater. Lett. 38245

[16] Ahmed A and Siores E 2001 J. Mater. Process. Technol. 118 88

[17] Dandapat N, Ghosh S, Pal K S, Datta S and Guha B K 2014 Trans. Nonferrous. Met. Soc. China 24 1666

[18] Ghosh S, Chakraborty R, Dandapat N, Pal K S, Datta S and Basu D 2012 Ceram. Int. 38663

[19] Ramins P and Ebihara B T 1989 IEEE Trans. Electron. Devices 36817

[20] Mishra R R, Rajesh S and Sharma A K 2014 Int. J. Adv. Mech. Eng. 4315

[21] Agrawal D 2006 Sohn International Symposium Advanced Processing of Metals and Materials, New, Improved and Existing Technologies: Non-Ferrous Materials Extraction and Processing, Kongoli F and Reddy R G (eds) TMS (The Minerals, Metals \& Materials Society) vol 4

[22] Hao H, Wang Y, Jin Z and Wang X 1997 J. Mater. Sci. 32 5011

[23] Xiong H P, Mao W, Xie Y H, Guo W L, Li X H and Cheng Y Y 2007 Mater. Lett. 614662

[24] do Nascimento R M, Martinelli A E and Buschinelli A J A 2003 Cerâmica 49178

[25] ASTM 2009 D4541-09e1 ASTM International West Conshohocken, PA 